Article

\title{
Classification of Red Wines Produced from Zweigelt and Rondo Grape Varieties Based on the Analysis of Phenolic Compounds by UPLC-PDA-MS/MS
}

\author{
Anna Stój ${ }^{1, *}$, Ireneusz Kapusta ${ }^{2} \mathbb{D}$ and Dorota Domagała ${ }^{3}$ \\ 1 Department of Biotechnology, Microbiology and Human Nutrition, Faculty of Food Science and \\ Biotechnology, University of Life Sciences in Lublin, 8 Skromna Street, 20-704 Lublin, Poland \\ 2 Department of Food Technology and Human Nutrition, College of Natural Science, Rzeszów University, \\ 4 Zelwerowicza Street, 35-601 Rzeszów, Poland; ikapusta@ur.edu.pl \\ 3 Department of Applied Mathematics and Computer Science, Faculty of Production Engineering, \\ University of Life Sciences in Lublin, 28 Głęboka Street, 20-612 Lublin, Poland; \\ dorota.domagala@up.lublin.pl \\ * Correspondence: anna.stoj@up.lublin.pl; Tel.: +48-81-4623380
}

Academic Editors: José Sousa Câmara, Rosa Perestrelo and Jorge Pereira Received: 31 January 2020; Accepted: 12 March 2020; Published: 16 March 2020

\begin{abstract}
The authentication of grape variety from which wine is produced is necessary for protecting a consumer from adulteration and false labelling. The aim of this study was to analyze phenolic compounds in red monovarietal wines produced from Zweigelt (Vitis vinifera) and Rondo (non-Vitis vinifera) varieties while using the UPLC-PDA-MS/MS method and to assess whether these wines can be classified according to grape variety that is based on chemometric analysis. Fifty-five phenolic compounds belonging to five classes-anthocyanins, flavonols, flavan-3-ols, phenolic acids, and stilbenes - were identified and quantified in Zweigelt and Rondo wines. The wines of the Zweigelt variety were characterized by lower concentrations of phenolic compounds than those of the Rondo variety. Furthermore, wines of the Zweigelt variety contained the highest concentrations of flavan-3-ols, and wines of the Rondo variety-the highest concentrations of anthocyanins. Hierarchical cluster analysis (HCA) revealed that Zweigelt wines and Rondo wines formed two separate groups. The Rondo group was divided into two subgroups, differing in type of malolactic fermentation (spontaneous or induced). Phenolic compounds analysis by means of UPLC-PDA-MS/MS combined with HCA is a useful tool for the classification of red wines that were produced from Zweigelt and Rondo grape varieties, regardless of yeast strain and type of malolactic fermentation.
\end{abstract}

Keywords: sugars; organic acids; phenolic compounds; authentication; adulteration; false labelling

\section{Introduction}

Wines have high commercial value and they are produced in large volumes, thus they are potentially subjected to adulteration and mislabeling [1]. Typical kinds of wine adulterations are false declaration of variety, geographical origin, vintage, addition of sugar, water, glycerol, and colorants [2-6]. Wine authentication is important to the consumers and industry and it has the purpose of identifying fraud and confirming label declarations. Consumers require that the price of wine is determined by its quality and wine labelling accurately reflects the reliable information. In turn, honest producers expect to ensure fair play on the wine market $[1,2,7,8]$. Wines contain a large number of metabolites, e.g., sugars, organic acids, amino acids, polyphenols, and aroma compounds [9,10]. Metabolomics studies propose the analysis of metabolites to enable integration of all metabolic changes of wine throughout its processing to assure wine authentication [7]. 
Wine polyphenols are classified as flavonoids, including anthocyanins, flavan-3-ols, flavonols, flavones, flavanones, isoflavones, and non-flavonoids, comprising phenolic acids and stilbenes [11-13]. The phenolic profile of wines depends on the grape variety, the grapes at harvest, geographical origin (environmental conditions, including soil type, climate, solar radiation, altitude), viticultural practices, winemaking techniques, and aging [14-17]. The grapevine genome affects the concentration and composition of phenols in grapes and the enzymatic reactions that are involved in their biosynthesis are influenced by environmental factors and viticultural practices [18,19]. Polyphenolic profiles can be used as chemical markers of the grape variety $[4,8,20-22]$, the geographical origin $[4,20,21,23]$, and vintage $[8,20]$.

Different techniques of liquid chromatography have been used for the analysis of polyphenols in wines. These compounds are usually determined by HPLC with photodiode array detector (HPLC-PDA or DAD, depending on the manufacturer) [24-29], UPLC-PDA [30], HPLC coupled with electrospray ionization mass spectrometry (HPLC-ESI-MS) [21], or HPLC with fluorescence detection (HPLC-FLD) [31,32]. Regarding the sample preparation, some authors have used solid-phase extraction (SPE) with different types of cartridges, liquid-liquid extraction (LLE), or injections of the samples directly in HPLC without any preparation [27]. An advanced technologies, such as: LC-MSQTOF [33], LC-MS/MS [20], UPLC-MS/MS [34], UPLC-QTOF [35], and UPLC-PDA-MS/MS [36], several laboratories have recently used for polyphenols analysis. The introduction of UPLC revolutionized separation science. Significant advances in instrumentation and column technology were made to obtain an increase in resolution, speed, and sensitivity in liquid chromatography. a higher separation efficiency of sub-2- $\mu \mathrm{m}$ particle sorbents allows for faster chromatographic separation [30].

Chemometric methods are employed for data processing and they enable the classification of wines according to grape variety. Ma et al. (2014) [25] applied HCA with the use of phenolic components as variables for the successful clustering of red wines that were made of different grape varieties grown in China. a cluster was formed by Cabernet Sauvignon and Merlot wines, another by Cabernet Gernischt and Cinsault wines, and the third cluster by Gamay wines. Some authors applied canonical discriminant analysis (CDA) as a chemometric method for data processing. Jaitz et al. (2010) [20] correctly classified red wines that were produced of Blauer Portugieser, Blauer Wildbacher and Sankt Laurent varieties in 100\% and in 65\% - of Blauer Zweigelt, Blaufränkisch, and Blauburger varieties. The classification of wines of Blauer Zweigelt, Blaufränkisch, and Blauburger varieties was unacceptable because of low eigenvalues and low canonical correlation. The CDA results of Sun et al. (2015) [4] showed 100\% differentiation of red wines (Cabernet Sauvignon, Carmenère, Merlot, Cabernet Franc and Shiraz) according to grape variety. Žurga et al. (2019) [22] successfully used CDA in discriminating Croatian wines that were produced from two native grape varieties (Plavac mali from Teran wines), and their separation from wines of non-native varieties (Cabernet Sauvignon, Merlot). In turn, Ivanova-Petropulos et al. (2015) [24] grouped the red wines of Cabernet Sauvignon, Merlot, Syrah, and Vranac varieties while using PCA. Pisano et al. (2015) [21] showed that multivariate curve resolution-alternating least-squares (MCR-ALS) model allowed for the successful discrimination of red wines of Aspiran, Bonarda, Cabernet Sauvignon, Malbec, Merlot, Sangiovese, Syrah, and Tempranillo varieties, while the discriminant unfolded partial least-squares (D-UPLS) model adequately discriminated Cabernet Sauvignon, Malbec, and Merlot wines from the remaining wines.

There are known cases of false wine labelling with a more expensive grape variety. For example, the producers and trader from the southwest of France were found to be guilty of having supplied an American trader with mislabeled "Pinot Noir" wines [7,37]. When compared to wine countries, such as France, Italy, Spain, or Germany, growing the Vitis interspecific hybrids, well-adapted to cold climate, and more resistant to fungal-pathogens, is much more popular in Poland. One of the most-grown red grape hybrid is Rondo (non-Vitis vinifera). However, a small area is covered by noble grape varieties, such as Zweigelt (Vitis vinifera). The wines that are produced from the noble grape varieties are known for their high quality, but they do not possess a high resistance against fungal infections and winter frost [13,38-41]. In Poland, there is a possibility to label wine from the Rondo variety as Zweigelt 
variety to obtain higher profit. The aim of this study was to determine the phenolic compounds in red monovarietal wines from Zweigelt and Rondo varieties while using the UPLC-PDA-MS/MS method and assessing whether these wines can be classified according to grape variety with chemometric analysis. This is the first study regarding the possibility of varietal classification of red wines made in Poland. The study of wines began with determination of oenological parameters, such as: $\mathrm{pH}$, total acidity, sugars, and organic acids, which characterize wines and are directly correlated with its quality and stability.

\section{Results and Discussion}

This paper analyzed twenty wines that were produced from the Zweigelt and Rondo grape varieties. Zweigelt wines, in which alcoholic fermentation was carried out by various yeast strains and malolactic fermentation was spontaneous had Z1-Z5 codes, while Zweigelt wines, in which alcoholic fermentation was carried out by various yeast strains (but the same as in Z1-Z5 wines) and malolactic fermentation was induced had Z1 LAB-Z5 LAB codes. We produced and coded Rondo wines by analogy to Zweigelt wines (R1-R5 and R1 LAB-R5 LAB). We did not identify lactic acid bacteria strains carrying out spontaneous malolactic fermentation in this paper.

Table S1 shows the oenological parameters, such as sugars, organic acids, $\mathrm{pH}$, and total acidity in wines produced from the Zweigelt and Rondo varieties in the Supplementary Materials, and Figures S1-S6 show the chromatograms of sugars and organic acids. These parameters are related to the composition of grapes and changes taking place during vinification. They are used to characterize each wine, because they directly correlate with their quality and stability [36]. Generally, Rondo wines contained similar concentrations of glucose, fructose, tartaric acid, and they had similar values of $\mathrm{pH}$ and total acidity to those that were determined by other authors in wines of the same grape variety [34,36,38,42,43]. In addition, they contained higher concentrations of malic acid, acetic acid, citric acid, and lower concentrations of succinic acid. To date, no work has been published containing a value of oenological parameters in Zweigelt wines. In our research, Zweigelt wines contained glucose, while glucose was not detected in Rondo wines. In addition, they were characterized by lower malic acid and higher acetic acid levels.

Wines that were subjected to spontaneous malolactic fermentation (R1-R5 and Z1-Z5) contained more malic acid and less lactic acid, while wines that were subjected to induced malolactic fermentation (R1 LAB-R5 LAB and Z1 LAB-Z5 LAB)_vice versa. Thus, induced fermentation was more effective. On the other hand, malic acid has not been completely converted to lactic acid in both types of fermentation. This can be explained by the fact that lactic acid has antimicrobial activity and, at higher concentrations, it might also inhibit the lactic acid bacteria. O. oeni activity might be inhibited above a certain lactic acid concentration and, in the case of high-acid musts, a total reduction of malic acid can be impossible [43].

R1-R5 and Z1-Z5 wines contained succinic acid, while R1 LAB-R5 LAB and Z1 LAB-Z5 LAB wines did not have this acid. Based on the literature, one possibility is that all succinic acid was esterified to diethyl succinate in R1 LAB-R5 LAB and Z1 LAB-Z5 LAB wines. Succinic acid is produced during alcoholic fermentation, and it is esterified to diethyl succinate in wines that undergo malolactic fermentation. Diethyl succinate content was much higher in wines that underwent induced malolactic fermentation than in those that underwent spontaneous malolactic fermentation [44].

Table 1, Table S2, and Table S3 show phenolic compounds that were identified and quantified using UPLC-PDA-MS/MS in red wines produced from Zweigelt and Rondo varieties. Figure 1 shows a typical fragmentation pattern mechanism, Figures 2 and 3 show chromatograms of phenolic compounds, and Figures S7-S12 show single ion recording (SIR) of phenolic compounds. The wines of the Zweigelt variety contained lower concentrations of phenolic compounds than those of the Rondo variety. Wines of the Zweigelt variety contained the highest concentrations of flavan-3-ols, and wines of the Rondo variety - the highest concentrations of anthocyanins. The tested wines had average amounts of 
phenolic acids when compared to other classes of compounds. Flavonols and stilbenes were the minor compounds (Tables S2 and S3).

Table 1. UPLC-PDA-MS/MS identification parameters of phenolic compounds.

\begin{tabular}{|c|c|c|c|c|c|c|}
\hline No & Compound & Abbreviation & RT (min.) & $\underset{(m / z)}{[\mathbf{M}-\mathbf{H}]}$ & $\begin{array}{l}\text { Fragment } \\
\text { ions }(m / z)\end{array}$ & $\lambda \max (\mathrm{nm})$ \\
\hline \multicolumn{7}{|c|}{ Anthocyanins } \\
\hline 1 & Delphinidin 3-O-glucoside-5-O-glucoside & 35dGD & 2.04 & 627 & 465,303 & 277,525 \\
\hline 2 & Cyanidin 3-O-glucoside-5-O-glucoside & 35dGC & 2.19 & 611 & 449,287 & 280,516 \\
\hline 3 & Delphinidin 3-O-glucoside & $3 g D$ & 2.38 & 465 & 303 & 280,523 \\
\hline 4 & Petunidin 3-O-glucoside-5-O-glucoside & 35dGPet & 2.53 & 641 & 479,317 & 277,531 \\
\hline 5 & Peonidin 3-O-glucoside-5-O-glucoside & 35dGPeo & 2.67 & 625 & 463,301 & 278,513 \\
\hline 6 & Malvidin 3-O-glucoside-5-O-glucoside & 35dGM & 2.72 & 655 & 493,331 & 275,524 \\
\hline 7 & Cyanidin 3-O-glucoside & $3 \mathrm{gC}$ & 2.74 & 449 & 287 & 279,515 \\
\hline 8 & Petunidin 3-O-glucoside & $3 \mathrm{gPet}$ & 2.92 & 479 & 317 & 277,526 \\
\hline 9 & Peonidin 3-O-glucoside & $3 \mathrm{gPeo}$ & 3.31 & 463 & 301 & 279,515 \\
\hline 10 & Malvidin 3-O-glucoside & $3 g M$ & 3.43 & 493 & 331 & 278,530 \\
\hline 11 & Delphinidin 3-O-(6"'-O-acetyl)-glucoside & 3agD & 3.53 & 507 & 465,303 & 280,528 \\
\hline 12 & Cyanidin 3-O-(6" $6^{\prime \prime} O$-acetyl)-glucoside & 3agC & 3.95 & 491 & 449,287 & 283,522 \\
\hline 13 & Petunidin 3-O-(6" $-\mathrm{O}$-acetyl)-glucoside & 3agPet & 4.10 & 521 & 317 & 280,530 \\
\hline 14 & $\begin{array}{l}\text { Petunidin } \\
3-O-\left(6^{\prime \prime}-O \text {-acetyl }\right) \text {-glucoside-5-O-glucoside }\end{array}$ & $3 a g 5 \mathrm{gPet}$ & 4.28 & 787 & $625,479,317$ & 280,530 \\
\hline 15 & Delphinidin 3-O-(6"-O-coumaryl)-glucoside & $3 \mathrm{kgD}$ & 4.47 & 611 & 303 & 279,530 \\
\hline 16 & Malvidin 3-O-(6" $-O$-acetyl $)$-glucoside & 3agM & 4.62 & 535 & 331 & 280,521 \\
\hline 17 & $\begin{array}{l}\text { Malvidin } \\
\text { 3-O-(6"-O-coumaryl)-glucoside-5-O-glucoside }\end{array}$ & $3 \mathrm{~kg} 5 \mathrm{gM}$ & 4.67 & 801 & $639,493,331$ & 280,530 \\
\hline 18 & $\begin{array}{l}\text { Peonidin } \\
\text { 3-O-(6"'-O-coumaryl)-glucoside-5-O-glucoside }\end{array}$ & $3 \mathrm{~kg} 5 \mathrm{gPeo}$ & 4.68 & 771 & $609,463,301$ & 279,523 \\
\hline 19 & Peonidin $3-O-\left(6^{\prime \prime}-O\right.$-acetyl $)$-glucoside & 3agPeo & 4.85 & 505 & 463,301 & 277,535 \\
\hline 20 & Cyanidin 3-O-(6" $-O$-coumaryl)-glucoside & $3 \mathrm{kgC}$ & 4.93 & 595 & 287 & 283,522 \\
\hline 21 & Petunidin 3-O-(6" $-O$-coumaryl $)$-glucoside & $3 \mathrm{kgPet}$ & 4.98 & 625 & 317 & 280,531 \\
\hline 22 & Delphinidin 3-O-(6"'-caffeoyl)-glucoside & 3cafGD & 5.35 & 627 & 465,303 & 280,528 \\
\hline 23 & Peonidin 3-O-(6" $6^{\prime \prime}-$-coumaryl $)$-glucoside & $3 \mathrm{kgPeo}$ & 5.39 & 609 & 301 & 279,523 \\
\hline \multicolumn{7}{|c|}{ Flavonols } \\
\hline 25 & Myricetin-3-O-rutinoside & 3-RutM & 4.08 & 625 & 479,317 & 255,353 \\
\hline 26 & Myricetin-3-O-glucoside & 3-GM & 4.24 & 479 & 317 & 255,353 \\
\hline 27 & Quercetin 3-O-glucuronide & 3-GluQ & 4.48 & 477 & 301 & 255,356 \\
\hline 28 & Isorhamnetin 3-O-glucoside & 3-Giso & 4.67 & 447 & 315 & 254,369 \\
\hline 29 & Quercetin 3-O-glucoside & 3-GQ & 4.82 & 463 & 301 & 253,365 \\
\hline 30 & Quercetin 3-O-rutinoside & 3-RutQ & 4.99 & 609 & 447,301 & 255,355 \\
\hline \multicolumn{7}{|c|}{ Flavan-3-ols } \\
\hline 32 & Procyanidin B1 & ProcB1 & 2.66 & 577 & 425,285 & 280 \\
\hline 33 & Procyanidin B-type 1 & ProcB-type1 & 2.81 & 577 & 425,285 & 276 \\
\hline 34 & Procyanidin $\mathrm{C} 1$ & ProcC1 & 2.97 & 865 & 577,285 & 280 \\
\hline 35 & $(+)$ catechin & Cat & 3.01 & 289 & - & 280 \\
\hline 36 & Procyanidin C-type 1 & ProcC-type1 & 3.07 & 865 & 577,285 & 280 \\
\hline 37 & Procyanidin B-type 2 & ProcB-type2 & 3.31 & 577 & 285 & 279 \\
\hline 38 & Procyanidin B2 & ProcB2 & 3.34 & 577 & 285 & 280 \\
\hline 39 & (-) epicatechin & Epicat & 3.68 & 289 & - & 280 \\
\hline 40 & Procyanidin C-type 2 & ProcC-type2 & 3.74 & 865 & 577,289 & 279 \\
\hline 41 & Procyanidin C-type 3 & ProcC-type3 & 3.84 & 865 & 577,289 & 280 \\
\hline 42 & Procyanidin B-type 3 & ProcB-type3 & 4.06 & 577 & 289 & 279 \\
\hline 43 & \multicolumn{5}{|l|}{ Phenolic acids } & 280 \\
\hline 44 & Gallic acid & Gal & 1.47 & 169 & 125 & 272 \\
\hline 45 & Protocatechuic acid & Prot & 2.25 & 153 & 109 & 308 \\
\hline 46 & Caftaric acid & Caft & 2.49 & 311 & 179 & 328,294 \\
\hline 47 & Coutaric acid & Cout & 3.08 & 295 & 163 & 310 \\
\hline 48 & Caffeic acid & Caff & 3.46 & 153 & 109 & 260,294 \\
\hline 49 & Ferulic acid & Fer & 4.92 & 193 & 134 & 323,293 \\
\hline 50 & $p$-Coumaric acid & $p$-Coum & 4.39 & 163 & 119 & 308 \\
\hline 51 & Coumaric acid & Coum & 4.82 & 163 & 119 & 310 \\
\hline \multicolumn{7}{|c|}{ Stilbenes } \\
\hline 52 & Trans-piceid & Trans-P & 4.75 & 389 & 227 & 327 \\
\hline 53 & Cis-piceid & Cis-P & 5.94 & 389 & 227 & 327 \\
\hline 54 & Trans-resveratrol & Trans-R & 6.24 & 227 & 185 & 327 \\
\hline 55 & Cis-resveratrol & Cis-R & $\begin{array}{l}7.24 \\
7.42\end{array}$ & 227 & 143 & 327 \\
\hline
\end{tabular}

$m / z$ for anthocyanins have been obtained in the positive mode $\left([\mathrm{M}+\mathrm{H}]^{+}\right.$. 


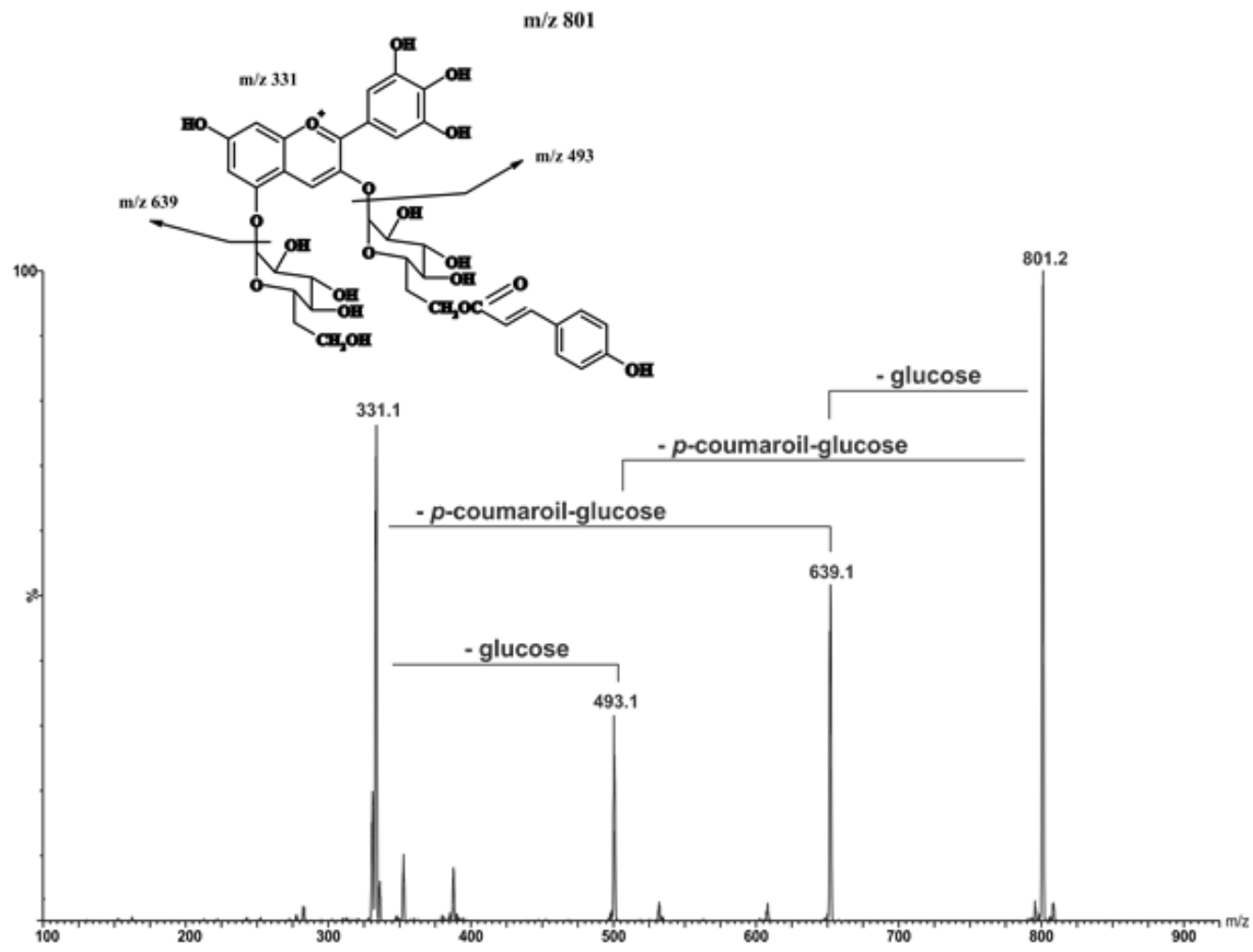

Figure 1. A typical fragmentation pattern mechanism based on the example of malvidine 3-O-(6'-O-coumaryl)-glucoside-5-O-glucoside.

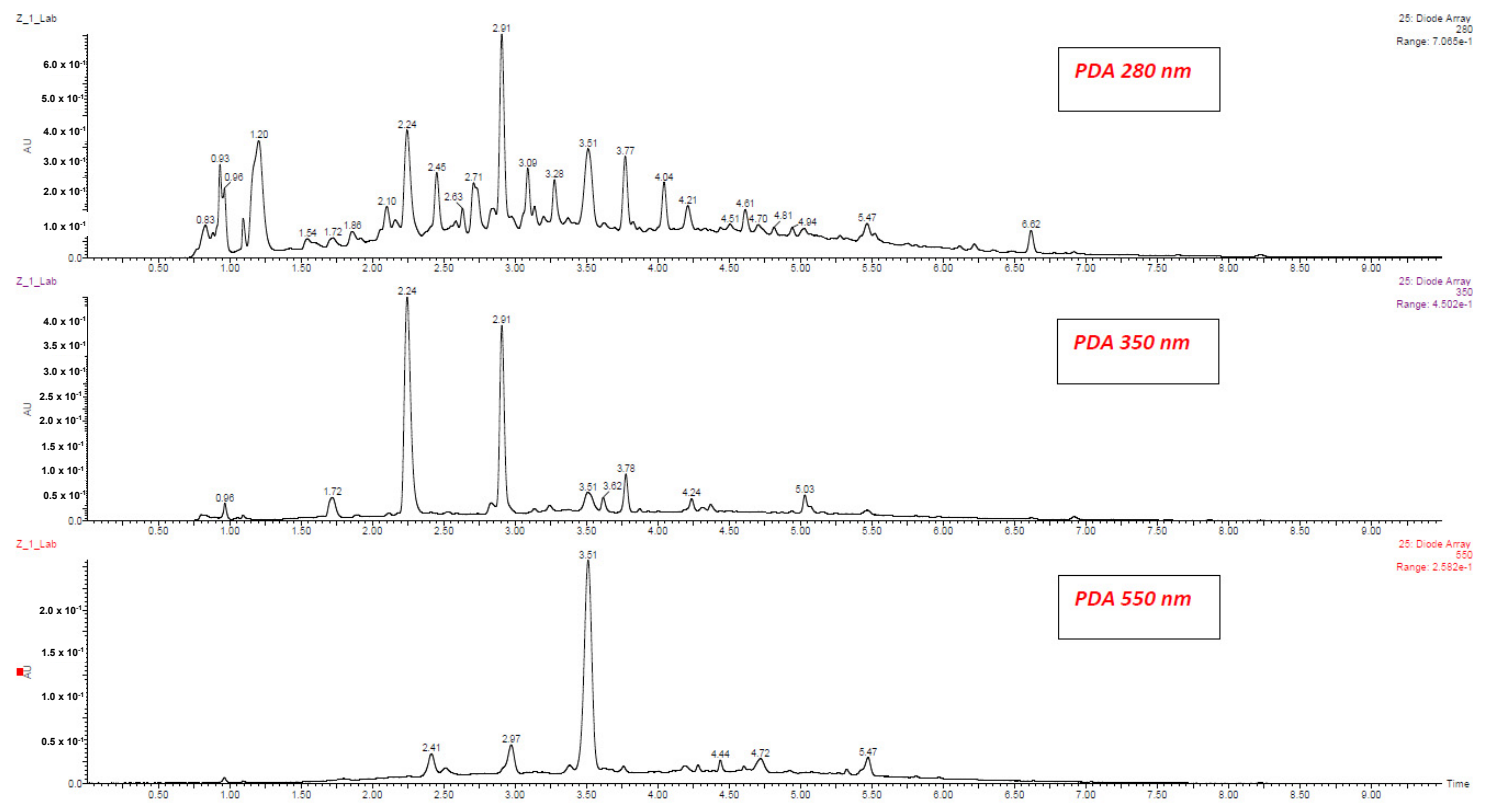

Figure 2. UPLC-PDA chromatograms of phenolic compounds in Zweigelt wine at 280, 350 and $550 \mathrm{~nm}$. 


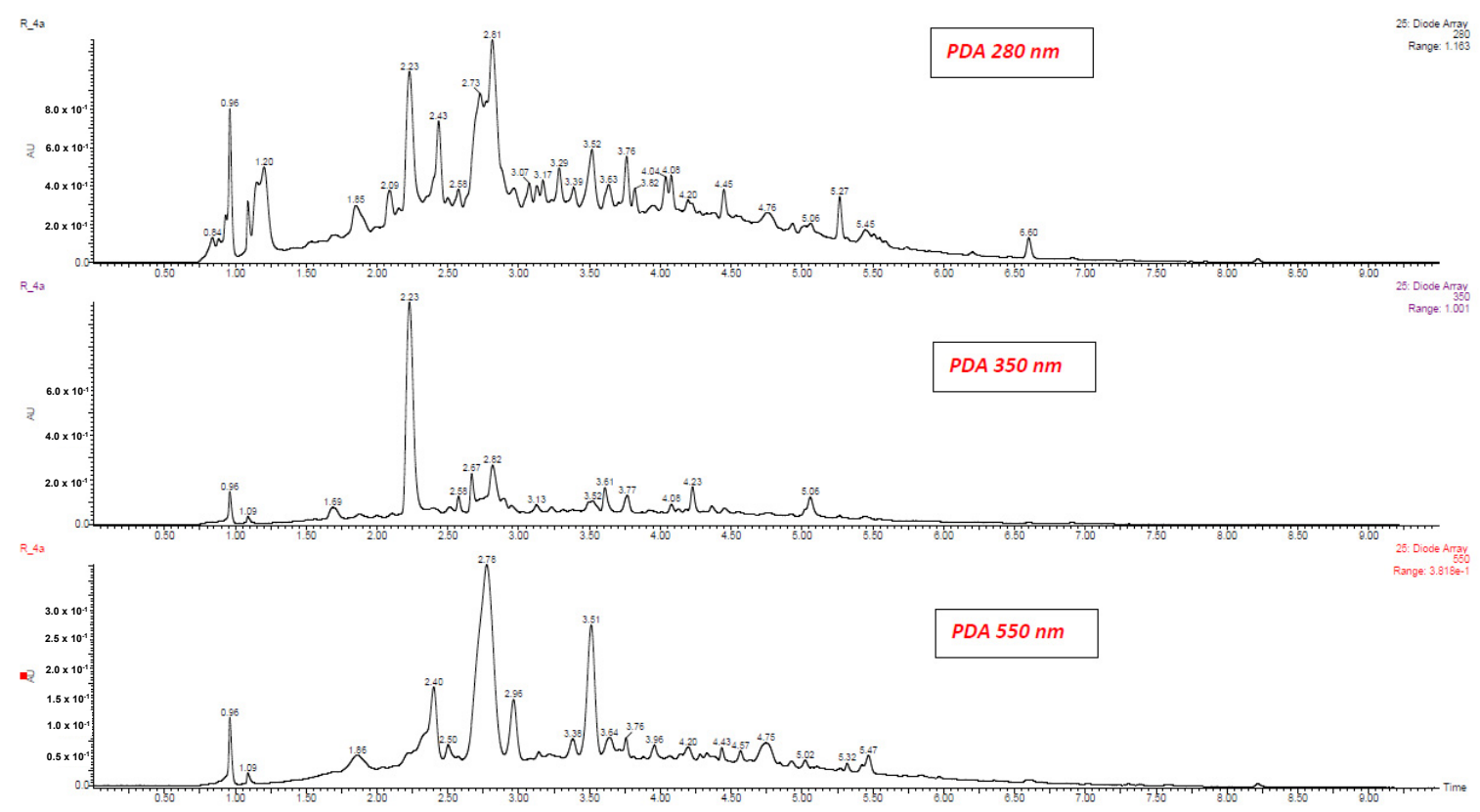

Figure 3. UPLC-PDA chromatograms of phenolic compounds in Rondo wine at 280, 350 and $550 \mathrm{~nm}$.

Anthocyanins constituted the most numerous class among phenolic compounds in wines from both grape varieties. a total of 24 anthocyanins were identified in tested wines, including derivatives of five aglycones: malvidin (5), delphinidin (5), cyanidin (4), peonidin (5), and petunidin (5). Among the compounds, there were mono- and diglucosides, their acylated derivatives, as well as combinations with p-coumaric acid, acetic acid, and caffeic acid. Anthocyanins are water-soluble pigments, which are only present in red grape skins (the entirety of anthocyanins in grapes is made of the derivatives of the five aglycones), being transferred to red wines during vinification (maceration). The presence of anthocyanin diglucosides in red wines, particularly malvidin-3,5-diglucoside, is a quality marker that is used for distinguishing wines produced from $V$. vinifera and non- $V$. vinifera grapes. $V$. vinifera wines contain significant quantities of anthocyanin monoglucosides, on the contrary to non- $V$. vinifera wines, which contain significant quantities of anthocyanin diglucosides [13,36]. In our study, Zweigelt (V. vinifera) wines had high concentrations of anthocyanin monoglucosides, such as malvidin 3-O-glucoside, delphinidin 3-O-glucoside, and petunidin 3-O-glucoside, while Rondo (non- $V$. vinifera) wines had high concentrations of malvidin 3-O-glucoside-5-O-glucoside, peonidin 3-O-glucoside-5-O-glucoside, and delphinidin 3-O-glucoside-5-O-glucoside. The anthocyanins diglucosides were also present at a low concentration in Zweigelt wines. The concentration of malvidin 3-O-glucoside-5-O-glucoside in Zweigelt wines was $0.33 \mathrm{mg} / \mathrm{L}$, which is in accordance with the limit of $15 \mathrm{mg} / \mathrm{L}$ that was stated by International Organization of Vine and Wine (OIV) [45]. a previous study of Kapusta et al. (2017) [46] also reported the presence of anthocyanin 3,5-O-diglucosides in Zweigelt grapes. Ivanova-Petropulos et al. (2015) [24] proposed the ratio of acetylglucosides and p-coumaroylglucosides $(\Sigma$ acetylated $/ \Sigma$ coumaroylated) as a verification factor for varietal authenticity of red wines. Values that were calculated by the authors in Macedonian wines ranged among regions: for native Vranec wines 1-1.7, for Syrah 2.6-4.8, for Cabernet Sauvignon 3.2-4.6 and for Merlot wine 2.3-3.8. In our study, $\Sigma$ acetylated/ $\Sigma$ coumaroylated ratio for Zweigelt wines was $0.6-1.1$ and for Rondo wines, it was $0.7-0.9$. Thus, our wines that were produced from grapes grown in Lublin Province cannot be distinguished based on this ratio. In turn, the $\Sigma$ acetylated $/ \Sigma$ coumaroylated ratio in Rondo wines that were made from grapes growing in Germany was 0.5-1.4 [34].

Twelve compounds that belonged to the class of flavan-3-ols were identified in the wines: two $(+)$ catechin and (-) epicatechin monomers, and ten procyanidins. The flavan-3-ols affect the bitterness, astringency, and structure of wines. Furthermore, they play an important role during ageing, because they stabilize wine color. Flavanols occur in solid parts of grapes (seed, skin, 
and stem). Like anthocyanins, flavan-3-ols significantly change during maceration and fermentation. The monomeric flavanols easily undergo the oxidation and condensation creating the procyanidin complex, thus decreasing their amount might be observed during crushing of grapes and before the beginning of the fermentation. Flavan-3-ols are extracted during the whole process of maceration and fermentation, in contrast to anthocyanins, which reach their maximum concentration at the beginning of fermentation, because extraction from seeds is slower than from skins. The ethanol concentration has little effect on extraction of flavan-3-ols from skins, while it greatly accelerates the transition of these compounds from seeds to wine $[25,36]$. In our research, the ratio between $(+)$ catechin and (-) epicatechin in Rondo wines was 2:1, similarly like in wine that is made from the same grape variety studied by Kapusta et al. (2018) [36].

Eight compounds were found in the group of phenolic acids, which were represented by two classes: hydroxycinnamic acids (caftaric, coutaric, caffeic, $p$-coumaric, coumaric, and ferulic) and hydroxybenzoic acids (gallic and protocatechuic). Gallic acid is a major phenolic acid in red wines. The biosynthesis of flavanols influences concentrations of gallic acid in grapes, in particular (+)-gallo(catechins) and (-)-epi(gallo)catechins, which in turn are hydrolyzed to gallic acid, under the action of tannase enzymes. Thus, the grape variety used for a winemaking process and climatic conditions during cultivation have significant influence on the concentration of this phenolic acid [28, $36,40]$. In our work, wines that are made from the Rondo variety contained higher amounts of gallic acid than Zweigelt wines.

Seven compounds represent the flavonols in the wines, which included derivatives of quercetin (3), myricetin (2), dihydroquercetin (1), and isorhamnetin (1). The flavonols are colorless, but they contribute to the color stabilization of red wines due to co-pigmentation with anthocyanins. They also contribute to wine bitterness [25]. They originate from the grape skins of both white and red grapes. Higher concentrations of flavonols are observed in red wines subjected to maceration $[19,25,36]$. In our research, the red wines of both varieties mainly contained isorhamnetin 3-O-glucoside and myricetin-3-O-glucoside.

Stilbenes were the last group of analyzed polyphenolic compounds in the wines. Among this group, the cis- and trans-isomers of resveratrol and its glycoside derivatives, piceid, were identified. Stilbenes are an important class of phenolic compounds due to their protective effects against cardiovascular diseases $[19,25]$. Wine is the main source of resveratrol in human diet. The amount of stilbenes in wine varies widely, depending on many factors, including grape variety, plant stress conditions (such as pathogens and ultraviolet light), oenological practices, and enzymatic activity of yeast and lactic acid bacteria $[22,28,36]$. In our study, the Rondo and Zweigelt wines differed in the content of individual stilbenes, especially trans-piceid and cis-piceid. Furthermore, the influence of yeast strain and type of malolactic fermentation (spontaneous or induced) on trans-piceid content was observed within the wines of the Zweigelt as well as Rondo variety.

The concentrations of the total phenolic compounds in wines that were produced from Zweigelt variety ranged from 128.02 to $273.62 \mathrm{mg} / \mathrm{L}$. While considering concentration of phenolic compounds, wines of the Zweigelt variety contained the highest concentrations of flavan-3-ols, followed by anthocyanins, phenolic acids, stilbenes, and flavonols. The subtotal concentration of flavan-3-ols varied from 68.62 to $132.38 \mathrm{mg} / \mathrm{L}$, for anthocyanins from 22.34 to $120.05 \mathrm{mg} / \mathrm{L}$, for phenolic acids from 24.20 to $33.29 \mathrm{mg} / \mathrm{L}$, for stilbenes from 2.09 to $3.43 \mathrm{mg} / \mathrm{L}$, and for flavonols from 0.32 to $0.70 \mathrm{mg} / \mathrm{L}$. The fraction of flavan-3-ols mainly composed of $(-)$ epicatechin and $(+)$ catechin, anthocyanins-of malvidin 3-O-glucoside, phenolic acids-of gallic acid and caftaric acid, stilbenes-of cis-resveratrol, and flavonols-of isorhamnetin 3-O-glucoside and myricetin-3-O-glucoside. Quercetin 3-O-glucuronide and dihydroquercetin 3-O-ramnoside were not detected in any wine produced from Zweigelt variety. Quercetin 3-O-rutinoside was found in two of all ten wines from the Zweigelt variety. a literature review shows that Jaitz et al. (2010) only examined phenolic compounds of Zweigelt wines [20]. The grapes for production of wines were grown in eleven different wine regions in Austria during five vintages from 2003 to 2007. These authors determined the 
content of several phenolic compounds: gallic acid, caffeic acid, catechin, epicatechin, cis-resveratrol, and trans-resveratrol. Our Zweigelt wines produced from grapes growing in Poland contained similar amounts of gallic acid, catechin and cis-resveratrol to those that were determined by Jaitz et al. (2010) [20]. The differences between the contents of caffeic acid, epicatechin, and trans-resveratrol may have been due to different geographical origins and related differences in climatic conditions during cultivation.

Wines that were produced from Rondo variety contained between 573.25 and $655.12 \mathrm{mg} / \mathrm{L}$ of total phenolic compounds. The wines of the Rondo variety had the highest concentrations of anthocyanins, followed by flavan-3-ols, phenolic acids, stilbenes, and flavonols. The subtotal concentration of anthocyanins ranged from 390.91 to $445.76 \mathrm{mg} / \mathrm{L}$, which was mainly due to the concentrations of malvidin 3-O-glucoside-5-O-glucoside and malvidin 3-O-glucoside. The concentration of flavan-3-ols varied from 113.98 to $177.23 \mathrm{mg} / \mathrm{L}$. The flavan-3-ols that were found in appreciable concentrations in the wines were $(+)$ catechin, procyanidin B-type 3 and procyanidin B1. The subtotal concentration of phenolic acids ranged from 32.16 to $45.98 \mathrm{mg} / \mathrm{L}$. This class of phenolic compounds was mainly composed of gallic acid and caftaric acid. No ferulic acid was found in one wine that was produced from Rondo variety, whereas, in the remaining nine wines, the concentrations of this acid were low. The concentration of stilbenes varied from 7.43 to $10.31 \mathrm{mg} / \mathrm{L}$. Cis-piceid was the first abundant stilbene and cis-resveratrol was the second one. The subtotal content of flavonols ranged from 1.50 to $2.18 \mathrm{mg} / \mathrm{L}$. Isorhamnetin 3-O-glucoside and myricetin-3-O-glucoside were the main flavonols. In recent years, several papers have been published regarding the content of phenolic compounds in wines that were produced from the Rondo variety. Similar to our studies, Ruocco et al. (2019) [34] and Kapusta et al. (2018) [36] found that anthocyanins constituted the largest class of phenolic compounds in Rondo wines, mainly malvidin 3-O-glucoside-5-O-glucoside and malvidin 3-O-glucoside. Furthermore, catechin was one of the main flavan-3-ols and caftaric acid was one of the main phenolic acids. Myricetin-3-O-glucoside was one of the most abundant flavonols in our study, which is in agreement with Kapusta et al. (2018) [36]. On the contrary, Ruocco et al. (2019) [34] and Kapusta et al. (2018) [36] showed low concentrations of isorhamnetin 3-O-glucoside. Similarly, cis-piceid and cis-resveratrol were found in significant amounts in wines that were tested by Kapusta et al. (2018) [36], while Ruocco et al. (2019) [34] determined significant amounts of cis-piceid, while not detecting cis-resveratrol. In our work, the contents of $(+)$ catechin, (-) epicatechin, gallic acid, caffeic acid, and p-coumaric acid in Rondo wines differed from the contents of these compounds in wine of the same grape variety that was tested by Socha et al. (2015) [40]. Only ferulic acid contents were similar. This could be due to the differences in sample preparation and chromatographic conditions between these studies.

The Student's t-test and Mann-Whitney test revealed significant differences in the content of anthocyanins, flavonols, and stilbenes among wines the produced from Zweigelt and Rondo varieties. The application of these tests was possible because the Liliefors test used earlier did not reject the hypothesis of normally distributed data. In the case of phenolic acids, only Gal and Prot were significant, while in the flavan-3-ols group, statistical significance was detected in Cat, Epicat, ProcB1, ProcB-type2, ProcB-type3, ProcB-type4, ProcC1, ProcC-type1, ProcC-type 2 (Tables S2 and S3). Then the PCA was performed to the data set by using these 46 significant compounds as variables. PCA revealed that the two first principal components explained $93.14 \%$ of the total variance. The first PC accounts for $87.11 \%$ and the second PC for $6.03 \%$ of the variance. a plot of the scores of PC1 versus PC2 (Figure 4 ) demonstrated that the wines of Rondo and Zweigelt formed two completely separate groups. Moreover, in the group of Rondo wines, the wines that had undergone spontaneous malolactic fermentation were separated from the wines that had undergone induced malolactic fermentation. 


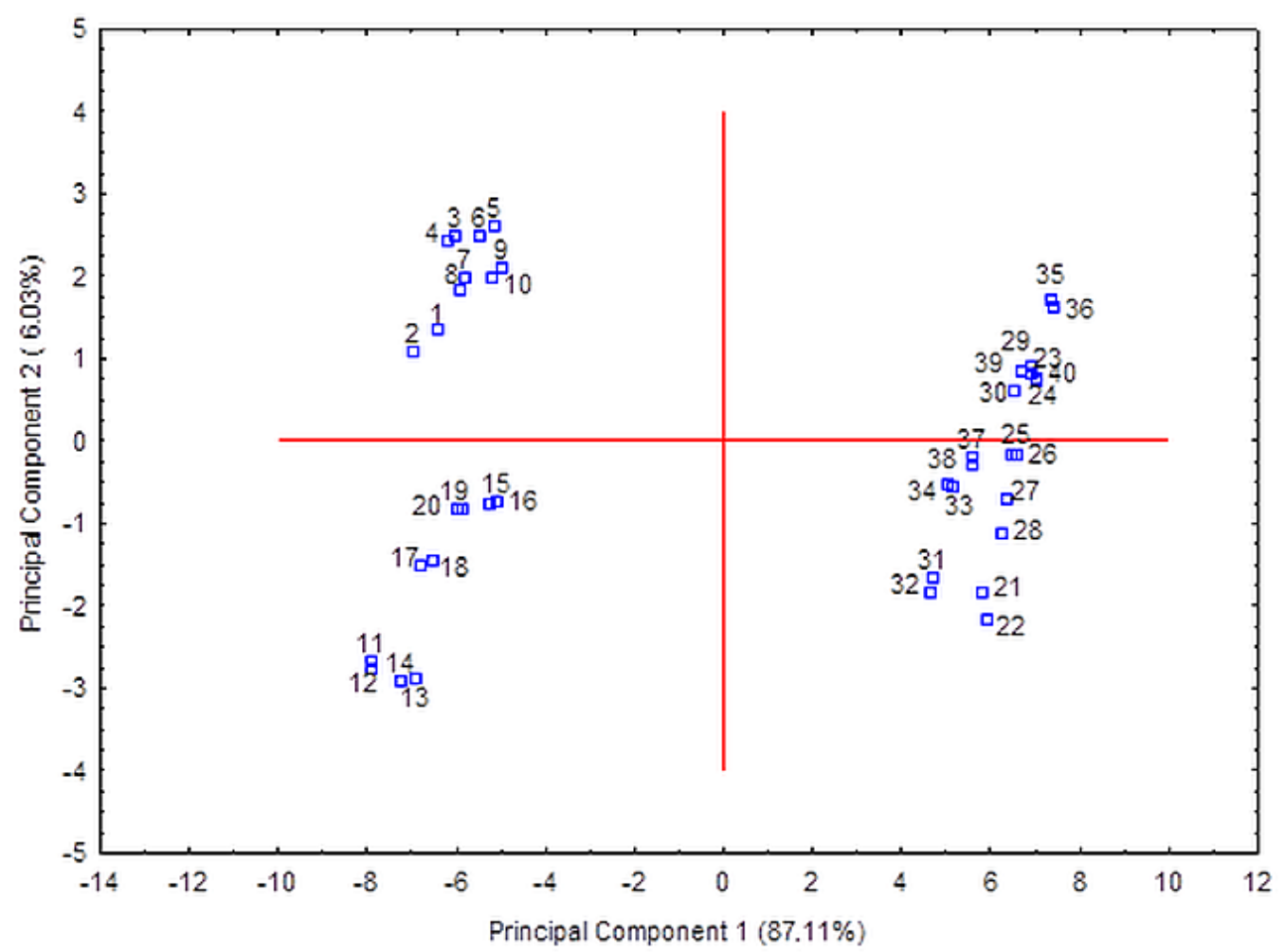

Figure 4. Score plot of wine samples on the PCA plane defined by the first two principal components (R1-R5 wines: 1-10, R1 LAB-R5 LAB wines: 11-20, Z1-Z5 wines: 21-30, Z1 LAB-Z5 LAB wines: 31-40; see Table 1 for phenolic compounds names).

After analyzing the basic descriptive statistics and the distance between observations from both groups of wines, the compounds that best differentiated the tested wines were selected: from the stilbenes group-Cis-P and Cis-R, from the flavonols group-3-Giso, 3-RhadQ, and 3GluQ, from the flavan-3-ols group-ProcC1 and ProcC-type2, from the phenolic acids group-Prot and Gal. In the case of anthocyanins, the best differentiating compounds (the largest distance between observations) were 35dGM, 35dGPeo, 3gD, 35dGD, and 35dGPet due to their number and because they all are significant. HCA was performed in order to analyze the similarity between examined wines. Their number had to be reduced due to excess of significant variables. First, principal component analysis (PCA) was performed to show correlations between variables (Figure 5). The majority of them are strongly correlated with each other. While considering results of PCA and HCA, the variables were divided into four groups. The first contained only Trans-P, the second-Epicat and ProcB-type2, the third-Cat, ProcB1, Trans-R, ProcC-type1, and the fourth-all other compounds: 35dGC, 35dGD, 35dGM, 35dGPeo, 35dGPet, 3ag5gPet, 3agC, 3agD, 3agM, 3agPeo, 3agPet, 3cafGD, 3gC, 3gD, 3gM, 3gPeo, 3gPet, 3kg5gM, 3kg5gPeo, 3kgC, 3kgD, 3kgM, 3kgPeo, 3kgPet, 3-Giso, 3-GM, 3-GQ, 3-RhadQ, 3-GluQ, 3-RutM, 3-RutQ, Cis-P, Cis-R, Gal, Prot, ProcB-type3, ProcB-type4, ProcC1, and ProcC-type2. Subsequently, the representative of each of four groups was selected. The representative of the first group was Trans-P variable. PCA was applied for variables from these groups to find the representatives of the other three groups. The first principal component was chosen to be the representative of each group. The reduction of variable numbers did not cause any significant loss of information-a maximum of $6.63 \%$ for the fourth most numerous group. The wines' clustering revealed that wines made from Zweigelt and Rondo grapes formed two separate groups, the Rondo group was divided into two subgroups that differed in the type of malolactic fermentation. The wines that were produced from one grape variety showed greater similarity while taking into account phenolic compounds than those produced from different varieties (Figure 6). 


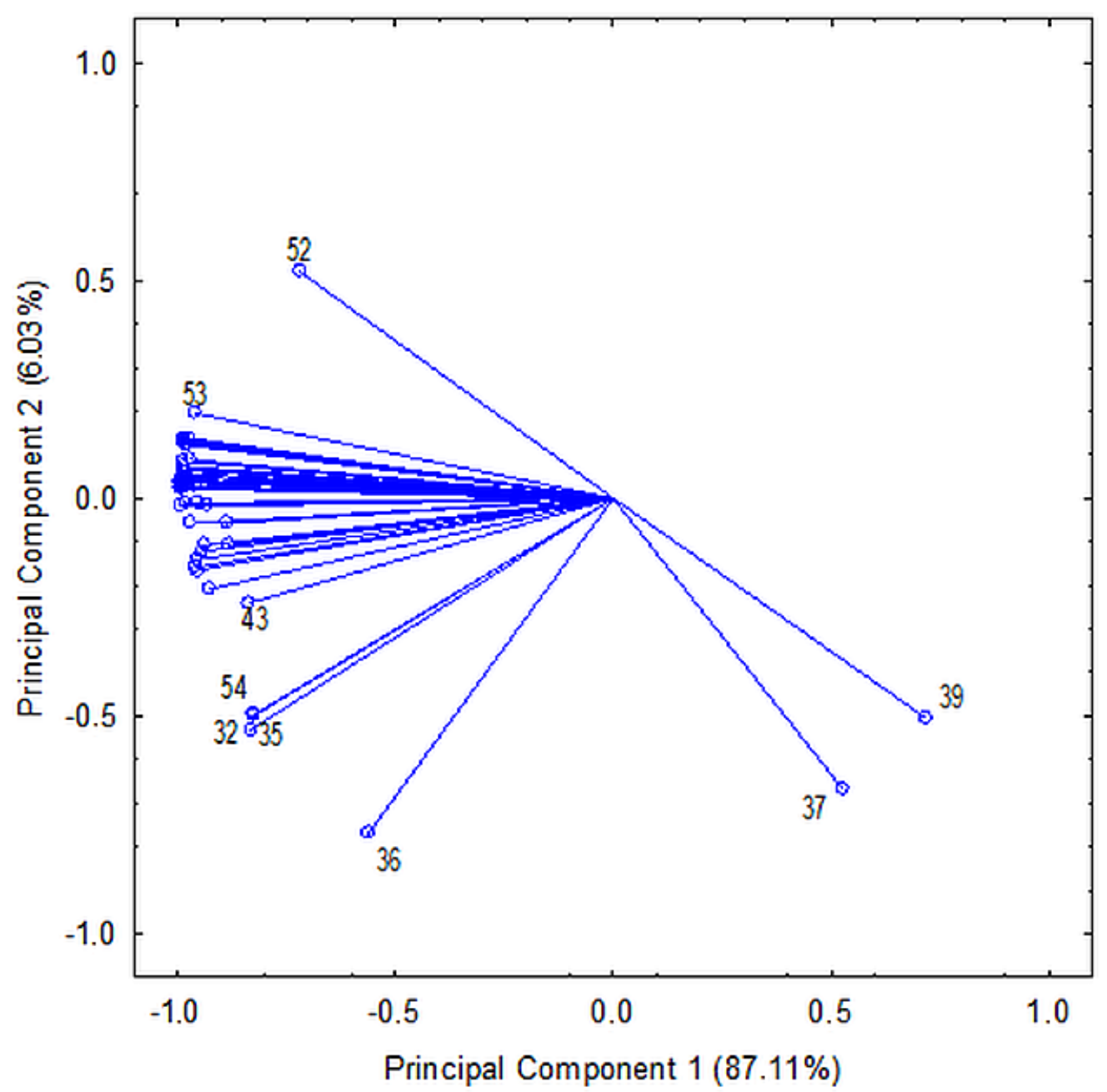

Figure 5. Projection of variables on the PCA plane (in order to improve clarity of the drawing, the following numbers of compounds, which were placed between compound No. 53 and 43, have been omitted: 1-31, 34, 40, 42, 44, 45, and 55; see Table 1 for phenolic compounds names). 


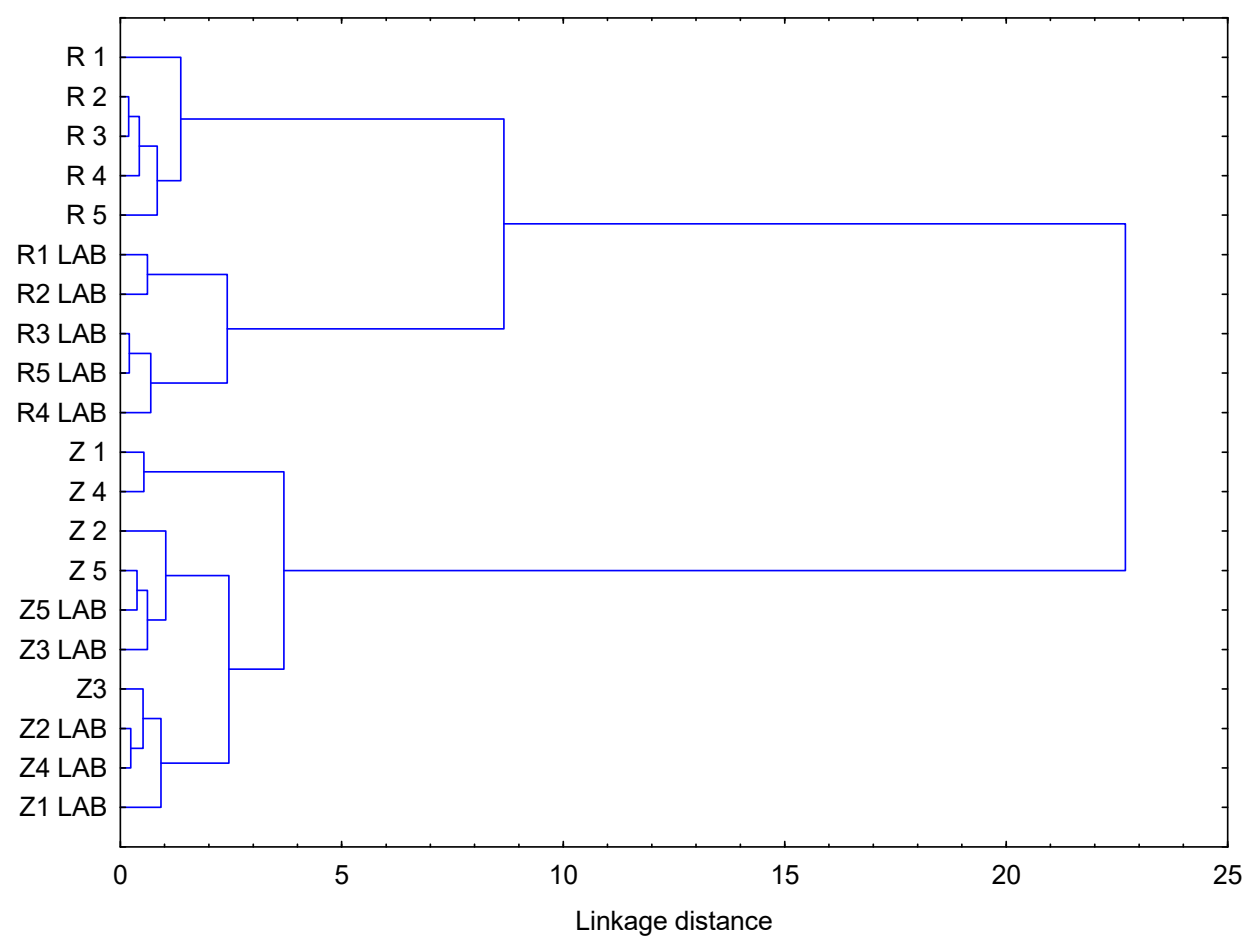

Figure 6. Dendrogram showing clustering of wines made of Zweigelt and Rondo varieties (R1-R5-wines from the Rondo variety, in which alcoholic fermentation was carried out by different yeast strains and malolactic fermentation was spontaneous; R1 LAB-R5 LAB-wines from the Rondo variety, in which alcoholic fermentation was carried out by different yeast strains (but the same as in R1-R5 wines), and malolactic fermentation was induced; Z1-Z5-wines from the Zweigelt variety, in which alcoholic fermentation was carried out by different yeast strains and malolactic fermentation was spontaneous; Z1 LAB-Z5 LAB-wines from the Zweigelt variety, in which alcoholic fermentation was carried out by different yeast strains (but the same as in Z1-Z5 wines), and malolactic fermentation was induced).

\section{Materials and Methods}

\subsection{Chemicals}

Sodium hydroxide solution $(0.1 \mathrm{~mol} / \mathrm{L})$ was purchased from Sigma-Aldrich (Poznań, Poland). Buffer solutions of $\mathrm{pH} \mathrm{2,} 4$ and 7 were purchased from $\mathrm{POCH}$ (Gliwice, Poland). Sucrose, glucose, fructose, tartaric, malic, lactic, acetic, citric and succinic acids were obtained from Sigma-Aldrich (Poznań, Poland), all with a purity level of $\geq 98 \%$. Analytical standards of cyanidin-3-O-glucoside, peonidin-3-Oglucoside, petunidin-3-O-glucoside, malvidin-3-O-glucoside, delphinidin-3-O-glucoside, myricetin-3-O-glucoside, quercetin-3-O-rutinoside, quercetin-4'-O-glucoside, quercetin-3-O-glucoside, kaempferol-3-O-glucoside, isorhamnetin-3-O-glucoside, (+)-catechin, (-)-epicatechin, (-)-epicatechin-3-gallate, procyanidin A1 and A2, trans-resveratrol, and trans-piceid, were purchased from Extrasynthese (Lyon, France). The analytic standards of gallic acid, caftaric acid, protocatechuic acid, coutaric acid, caffeic acid, $p$-coumaric acid, and ferulic acid were purchased from PhytoLab (Vestenbergsgreuth, Germany). Acetonitrile (HPLC gradient grade) was purchased from $\mathrm{POCH}$ (Gliwice, Poland). Formic acid (LC-MS grade) was purchased from Fischer Scientific (Schwerte, Germany).

\subsection{Winemaking and Wine Samples}

The grapes of Zweigelt and Rondo varieties originated from 'Małe Dobre' and 'Dom Bliskowice' vineyards, respectively. The vineyards are located in the Lublin Province, Poland. The harvest was manually done in 2017. The grapes were taken to the laboratory, and then stalked, crushed, 
portioned, and transferred to $5 \mathrm{~L}$ fermentation vessels. The grapes from the Zweigelt variety were transferred to five fermentation vessels, and grapes from the Rondo variety to other five vessels. One of the following commercial Saccharomyces cerevisiae preparations: SafCEno ${ }^{\mathrm{TM}}$ SC 22, Essentiale Grand Cru (Lesaffre, France), Siha Active Yeast 8, Siha Rubino Cru (Eaton, Tinton Falls, NJ, USA), and S. cerevisiae $\times$ S. bayanus preparation-SafCEno ${ }^{\mathrm{TM}}$ HD $\mathrm{S} 62$ (Lesaffre, France), was added to one fermentation vessel with Zweigelt variety, according to the manufacturer's instructions. Similarly, the same yeast was added to fermentation vessels with Rondo variety. The fermentation vessels were closed with stoppers and fermentation tubes. The alcoholic fermentations were conducted at $22-24{ }^{\circ} \mathrm{C}$ and then monitored by weight loss starting at inoculation and continuing every $24 \mathrm{~h}$ until the weight was stabilized. At the end of fermentation, each wine was pressed with a basket press and divided into two vessels. Oenococcus oeni preparation-Viniflora Oenos (Eaton, Tinton Falls, NJ, USA) was added to wine in one vessel and malolactic fermentation was carried out (induced malolactic fermentation). The lactic acid bacteria were not added to the wine in the second vessel (spontaneous malolactic fermentation). Table 2 presents a description of wines. Wines in both vessels were decanted, potassium metabisulfite at a dose of $60 \mathrm{mg} / \mathrm{L}$ was added, and wines were placed at $15^{\circ} \mathrm{C}$ for eight weeks. Subsequently, wines were decanted again and the temperature was lowered to $8^{\circ} \mathrm{C}$ for 4 weeks. After this, the wines were decanted, potassium metabisulfite at a dose of $60 \mathrm{mg} / \mathrm{L}$ was added, and the wines were bottled and stored at $15^{\circ} \mathrm{C}$ until analysis.

Table 2. Description of wine samples.

\begin{tabular}{|c|c|c|c|}
\hline Wine Code & Grape Variety & Yeast & Lactic Acid Bacteria \\
\hline $\mathrm{Z} 1$ & Zweigelt & SafCEno ${ }^{\text {TM }}$ SC 22 & - \\
\hline Z1 LAB & Zweigelt & SafEEno ${ }^{\text {TM }}$ SC 22 & Viniflora Oenos \\
\hline $\mathrm{Z} 2$ & Zweigelt & SafCEno ${ }^{\text {TM }}$ HD S62 & - \\
\hline Z2 LAB & Zweigelt & SafCEno ${ }^{\mathrm{TM}}$ HD S62 & Viniflora Oenos \\
\hline $\mathrm{Z3}$ & Zweigelt & Essentiale Grand Cru & - \\
\hline Z3 LAB & Zweigelt & Essentiale Grand Cru & Viniflora Oenos \\
\hline Z4 & Zweigelt & Siha Active Yeast 8 & - \\
\hline Z4 LAB & Zweigelt & Siha Active Yeast 8 & Viniflora Oenos \\
\hline $\mathrm{Z} 5$ & Zweigelt & Siha Rubino Cru & - \\
\hline Z5 LAB & Zweigelt & Siha Rubino Cru & Viniflora Oenos \\
\hline $\mathrm{R} 1$ & Rondo & SafCEno ${ }^{\text {TM }}$ SC 22 & - \\
\hline R1 LAB & Rondo & SafCEno ${ }^{\text {TM }}$ SC 22 & Viniflora Oenos \\
\hline $\mathrm{R} 2$ & Rondo & SafCEno ${ }^{\text {TM }}$ HD S62 & - \\
\hline R2 LAB & Rondo & SafCEno ${ }^{\text {TM }}$ HD S62 & Viniflora Oenos \\
\hline $\mathrm{R} 3$ & Rondo & Essentiale Grand Cru & - \\
\hline R3 LAB & Rondo & Essentiale Grand Cru & Viniflora Oenos \\
\hline $\mathrm{R} 4$ & Rondo & Siha Active Yeast 8 & - \\
\hline R4 LAB & Rondo & Siha Active Yeast 8 & Viniflora Oenos \\
\hline R5 & Rondo & Siha Rubino Cru & - \\
\hline R5 LAB & Rondo & Siha Rubino Cru & Viniflora Oenos \\
\hline
\end{tabular}

\subsection{Determination of Oenological Parameters}

The total acidity was determined according to OIV-MA-AS313-01 method while using potentiometric titration and expressed as g of tartaric acid in L [47] and the $\mathrm{pH}$ was determined according to OIV-MA-AS313-15 [48].

A HPLC system (Shimadzu, Kyoto, Japan) that consisted of a DGU-20A3 mobile phase degasser, two LC-20AD pumps, a CBM20A communication module, a SIL-20ACHT autosampler, a CTO-20AC column oven, a RID-10A refractive index detector, SPD-M20A photodiode array detector, and LCsolution program was used for the analysis of sugars and organic acids in wine samples. The wine samples before injection were degassed in an ultrasonic water bath, and then filtered through a $0.45 \mu \mathrm{m}$ SimplePure PTFE syringe filters (Membrane Solutions, Auburn, WA, USA) and diluted with deionized water at 1:4 ratio $(v / v)$. The separation of sugars was performed with isocratic elution on 
a cation exchange chromatography column Rezex RCM-Monosacharide Ca++ (300 mm $\times 7.8 \mathrm{~mm}$, $5 \mu \mathrm{m}$ particle size). Mobile phase was EDTA calcium disodium salt at a concentration of $0.1 \mathrm{mmol} / \mathrm{L}$ in deionized water, at a flow rate of $0.6 \mathrm{~mL} / \mathrm{min}$. The temperature of the column was maintained at $70{ }^{\circ} \mathrm{C}$. The volume of injected sample was $5 \mu \mathrm{L}$ and the time of analysis was $25 \mathrm{~min}$. a refractive index detector was used for the identification and quantification of sugars. The separation of organic acids was achieved in isocratic mode with a mobile phase of phosphate solution in deionized water containing $50 \mathrm{mM} \mathrm{H}_{3} \mathrm{PO}_{4}$ and $10 \mathrm{mM} \mathrm{NaH}_{2} \mathrm{PO}_{4}$ at $\mathrm{pH} 1.9$. The flow rate was $0.6 \mathrm{~mL} / \mathrm{min}$. The Luna 5 u C18 (2) Phenomenex chromatographic column $(250 \mathrm{~mm} \times 4.6 \mathrm{~mm}, 5 \mu \mathrm{m}$ particle size), which was set at $20{ }^{\circ} \mathrm{C}$, was used. The volume of injected sample was $20 \mu \mathrm{L}$ and time of analysis was $30 \mathrm{~min}$. The identification and quantification of organic acids were done using photodiode array detector at $214 \mathrm{~nm}$. Stock standard solutions of $10 \mathrm{~g} / \mathrm{L}$ for sugars and $8 \mathrm{~g} / \mathrm{L}$ for organic acids were prepared by dissolving each sugar and organic acid in deionized water. The working standard solutions were prepared by dilution with deionized water. The quantification was carried out using the external standard method. All of the determinations were performed in duplicate and expressed as $\mathrm{g} / \mathrm{L}$.

\subsection{Determination of Polyphenolic Compounds}

The analytical procedure was performed applying the method that was previously described by Kapusta et al. (2018) [36]. Polyphenolic compounds were analyzed while using ultra-performance reverse-phase liquid chromatography UPLC-PDA-MS/MS Waters ACQUITY system (Waters, Milford, MA, USA) consisting of a binary pump manager, sample manager, column manager, photodiode array (PDA) detector, and tandem quadrupole mass spectrometer (TQD) with electrospray ionization (ESI). The separation was carried out using a BEH C18 column $(100 \mathrm{~mm} \times 2.1 \mathrm{~mm}$ i.d., $1.7 \mu \mathrm{m}$, Waters $)$ that was kept at $50{ }^{\circ} \mathrm{C}$. For the anthocyanins investigation, the following solvent system was applied: mobile phase a ( $2 \%$ formic acid in water, $v / v)$ and mobile phase B ( $2 \%$ formic acid in $40 \% \mathrm{ACN}$ in water, $v / v)$. For other polyphenolic compounds, a lower concentration of formic acid was used $(0.1 \%, v / v)$. The gradient program was set, as follows: $0 \mathrm{~min}$. $5 \% \mathrm{~B}$, from 0 to $8 \mathrm{~min}$. linear to $100 \% \mathrm{~B}$, and from 8 to $9.5 \mathrm{~min}$. for washing and back to initial conditions. The injection volume of samples was $5 \mu \mathrm{L}$ (partial loop with needle overfill), and the flow rate was $0.35 \mathrm{~mL} / \mathrm{min}$. The following parameters were used for TQD: capillary voltage $3.5 \mathrm{kV}$, con voltage, $30 \mathrm{~V}$ in positive and negative mode; the source was kept at $120{ }^{\circ} \mathrm{C}$ and the desolvation temperature was $350{ }^{\circ} \mathrm{C}$, con gas flow $100 \mathrm{~L} / \mathrm{h}$, and desolvation gas flow $800 \mathrm{~L} / \mathrm{h}$. Argon was used as the collision gas at a flow rate of $0.3 \mathrm{~mL} / \mathrm{min}$. The polyphenolic detection and identification were based on specific PDA spectra, mass-to-charge ratio, and fragment ions obtained after collision-induced dissociation (CID). Before injection, the wine samples were filtered through a $0.45-\mu \mathrm{m}$ Millipore filter and then directly injected onto the chromatographic column. Quantification was achieved by the injection of solutions of known concentrations that ranged from 0.05 to $5 \mathrm{mg} / \mathrm{mL}\left(\mathrm{R}^{2} \leq 0.9998\right)$ of phenolic compounds as standards. All of the determinations were performed in duplicate and expressed as mg/L. Waters MassLynx software v.4.1 was used for data acquisition and processing.

The method was validated for parameters, such as: linearity, accuracy (relative error, RE), limit of detection (LOD), limit of quantification (LOQ), and precision (relative standard deviation, RSD). The stock solutions of five polyphenols were prepared by dissolving standards in methanol, followed by dilution to final solutions. The concentrations against peak area were plotted. The regression equation was obtained by the weighted least-squares linear regression. The LOD was determined as a signal-to-noise ratio $(\mathrm{S} / \mathrm{N})$ of 3:1, and the LOQ was determined as a S/N of 10:1. An acceptable RE within $\pm 20 \%$ and an RSD within $80-120 \%$ were obtained.

\subsection{Chemometric Analysis}

Data analysis was conducted using the Statistica 13.1 software package (StatSoft, Krakow, Poland). The Lilliefors test was carried out to examine whether the data come from the normally distributed population. The Student's t-test was used to examine whether there were any statistically 
significant differences between wines that were made from Zweigelt and Rondo varieties and whenever the Student's t-test assumptions regarding the homogeneity of variance were not fulfilled, the Mann-Whitney non-parametric test was applied. PCA was used to visualize eventual grouping of samples and also show correlations between variables. HCA was applied to explore similarity between tested wines. Clustering was performed by means of the Ward distance matrix that formed on the basis of the Euclidean distance.

\section{Conclusions}

Red wines that were produced from the Zweigelt ( $V$. vinifera) variety and Rondo (non- $V$. vinifera) variety were characterized in this paper. For the first time, the oenological parameters and the profile of phenolic compounds in Zweigelt wines were presented.

Phenolic compounds were determined while using the UPLC-PDA-MS/MS method. Zweigelt wines had high concentrations of anthocyanin monoglucosides, such as malvidin 3-O-glucoside, delphinidin 3-O-glucoside, and petunidin 3-O-glucoside, while the Rondo wines had high concentrations of malvidin 3-O-glucoside-5- $\mathrm{O}$-glucoside, peonidin 3-O-glucoside-5- $\mathrm{O}$-glucoside, and delphinidin 3-O-glucoside-5-O-glucoside. Wines that were made from the Rondo variety contained higher amounts of gallic acid than Zweigelt wines. Red wines of both varieties mainly contained isorhamnetin 3-O-glucoside, and myricetin-3-O-glucoside. The fraction of flavan-3-ols mainly composed of $(-)$ epicatechin and $(+)$ catechin in Zweigelt wines and of $(+)$ catechin, procyanidin B-type 3 and procyanidin B1 in Rondo wines. Rondo and Zweigelt wines differed in the content of individual stilbenes, especially trans-piceid and cis-piceid.

HCA revealed that wines that were made from Zweigelt and Rondo grapes formed two separate groups; the Rondo group was divided into two subgroups differing in the type of malolactic fermentation. Such results enhance the potential of HCA in detecting wine adulteration.

The determination of phenolic compounds using UPLC-PDA-MS/MS and HCA allowed for the classification of Zweigelt and Rondo wines, regardless of yeast strain and type of malolactic fermentation (spontaneous or induced). To date, no work has been published regarding the possibility of varietal classification of red wines made in Poland. Further research is needed on wines that are produced from Zweigelt and Rondo varieties that originated from different regions of Poland to show whether the wines can be classified independently of the region of origin.

Supplementary Materials: The following are available on line: Table S1: Oenological parameters of analyzed wines, Table S2: Concentration of phenolic compounds in wines produced from Zweigelt variety (in mg/L), Table S3: Concentration of phenolic compounds in wines produced from Rondo variety (in mg/L), Figure S1: Chromatogram of sugars in Rondo wine, Figure S2: Chromatogram of sugars in Zweigelt wine, Figure S3: Chromatogram of sugars standards, Figure S4: Chromatogram of organic acids in Rondo wine, Figure S5: Chromatogram of organic acids in Zweigelt wine, Figure S6: Chromatogram of organic acid standards, Figure S7: Single ion recording (SIR) of anthocyanins in Rondo wine detected by UPLC-MS/MS (part 1), Figure S8: Single ion recording (SIR) of anthocyanins in Rondo wine detected by UPLC-MS/MS (part 2), Figure S9: Single ion recording (SIR) of flavonols in Rondo wine detected by UPLC-MS/MS, Figure S10: Single ion recording (SIR) of flavan-3-ols in Rondo wine detected by UPLC-MS/MS, Figure S11: Single ion recording (SIR) phenolic acids in Rondo wine detected by UPLC-MS/MS, Figure S12: Single ion recording (SIR) of stilbenes in Rondo wine detected by UPLC-MS/MS

Author Contributions: Conceptualization, A.S.; methodology, A.S., I.K. and D.D.; validation, A.S., I.K. and D.D.; formal analysis, A.S., I.K. and D.D.; investigation, A.S., I.K. and D.D.; resources, A.S., I.K. and D.D.; data curation, A.S., I.K. and D.D.; writing-original draft preparation, A.S.; visualization, A.S., I.K. and D.D.; supervision, A.S. All authors have read and agreed to the published version of the manuscript.

Funding: This research received no external funding.

Acknowledgments: We would like to express our thankfullness to Adam Stręczywilk from Małe Dobre vineyard, Lech Mill and Maciej Sondij from Dom Bliskowice vineyard for providing grapes and for sharing specialist knowledge in the field of winemaking.

Conflicts of Interest: The authors declare no conflict of interest. 


\section{References}

1. Uttl, L.; Hurkova, K.; Kocourek, V.; Pulkrabova, J.; Tomaniova, M.; Hajslova, J. Metabolomics-based authentication of wines according to grape variety. Czech. J. Food Sci. 2019, 37, 239-245. [CrossRef]

2. Geană, E.I.; Ciucure, C.T.; Apetrei, C.; Artem, V. Application of Spectroscopic UV-Vis and FT-IR Screening Techniques Coupled with Multivariate Statistical Analysis for Red Wine Authentication: Varietal and Vintage Year Discrimination. Molecules 2019, 24, 4166. [CrossRef] [PubMed]

3. Stój, A. Metody wykrywania zafałszowań win. Żywność. Nauka. Technologia. Jakość. 2011, 75, 17-26.

4. Sun, X.; Li, L.; Ma, T.; Liu, X.; Huang, W.; Zhan, J. Profiles of phenolic acids and flavan-3-ols for select chinese red wines: a comparison and differentiation according to geographic origin and grape variety. J. Food Sci. 2015, 80, C2170-C2179. [CrossRef] [PubMed]

5. Palade, L.M.; Popa, M.E. Polyphenol fingerprinting approaches in wine traceability and authenticity: Assessment and implications of red wines. Beverages 2018, 4, 75. [CrossRef]

6. Pereira, L.; Gomes, S.; Barrias, S.; Gomes, E.P.; Baleiras-Couto, M.; Fernandes, J.R.; Martins-Lopes, P. From the Field to the Bottle-An Integrated Strategy for Wine Authenticity. Beverages 2018, 4, 71. [CrossRef]

7. Alañón, M.E.; Pérez-Coello, M.S.; Marina, M.L. Wine science in the metabolomics era. Trends Anal. Chem. 2015, 74, 1-20. [CrossRef]

8. Sen, I.; Tokatli, F. Authenticity of wines made with economically important grape varieties grown in Anatolia by their phenolic profiles. Food Control. 2014, 46, 446-454. [CrossRef]

9. Lorrain, B.; Ky, I.; Pechamat, L.; Teissedre, P.L. Evolution of analysis of polyhenols from grapes, wines, and extracts. Molecules 2013, 18, 1076-1100. [CrossRef]

10. Silva, C.L.; Pereira, J.; Wouter, V.G.; Giró, C.; Câmara, J.S. a fast method using a new hydrophilic-lipophilic balanced sorbent in combination with ultra-high performance liquid chromatography for quantification of significant bioactive metabolites in wines. Talanta 2011, 86, 82-90. [CrossRef]

11. Blancquaert, E.H.; Oberholster, A.; Ricardo-da-Silva, J.M.; Deloire, A.J. Effects of abiotic factors on phenolic compounds in the Grape Nerry-a review. S. Afr. J. Enol. Vitic. 2019, 40,1-14.

12. Ribereau-Gayon, P.; Glories, Y.; Maujean, A.; Dubourdieu, D. Handbook of Enology Volume 2 The Chemistry of Wine Stabilization and Treatments, 2nd ed.; Wiley: Chichester, UK, 2006; pp. 141-203.

13. Wojdyło, A.; Samoticha, J.; Nowicka, P.; Chmielewska, J. Characterisation of (poly)phenolic constituents of two interspecific red hybrids of Rondo and Regent (Vitis vinifera) by LC-PDA-ESI-MS QTof. Food Chem. 2018, 239, 94-101. [CrossRef] [PubMed]

14. Dumitru, B.F.; Bunea, C.I.; Călugăr, A.; Donici, A. Phenolic, anthocyanin composition and color measurement at red wines from Dealu Bujorului vineyard. Agricultura 2019, 109-110, 14-28.

15. Li, X.X.; He, F.; Wang, J.; Li, Z.; Pan, Q.H. Simple rain-shelter cultivation prolongs accumulation period of anthocyanins in wine grape berries. Molecules 2014, 19, 14843-14861. [CrossRef]

16. Urcan, D.E.; Lung, M.L.; Giacosa, S.; Torchio, F.; Ferrandino, A.; Vincenzi, S.; Río Segade, S.; Pop, N.; Rolle, L. Phenolic substances, flavor compounds, and textural properties of three native Romanian wine grape varieties. Int. J. Food Prop. 2016, 19, 76-98. [CrossRef]

17. Wu, Y.Y.; Xing, K.; Zhang, X.X.; Wang, H.; Wang, Y.; Wang, F.; Li, J.M. Influence of freeze concentration technique on aromatic and phenolic compounds, color attributes, and sensory properties of Cabernet Sauvignon wine. Molecules 2017, 22, 899. [CrossRef]

18. Coletta, A.; Trani, A.; Faccia, M.; Punzi, R.; Dipalmo, T.; Crupi, P.; Antonacci, D.; Gambacorta, G. Influence of viticultural practices and winemaking technologies on phenolic composition and sensory characteristics of Negroamaro red wines. Int. J. Food Sci. Tech. 2013, 48, 2215-2227. [CrossRef]

19. Fanzone, M.; Peña-Neira, A.; Jofré, V.; Assof, M.; Zamora, F. Phenolic characterization of Malbec wines from Mendoza province (Argentina). J. Agric. Food Chem. 2010, 58, 2388-2397. [CrossRef]

20. Jaitz, L.; Siegl, K.; Eder, R.; Rak, G.; Abranko, L.; Koellensperger, G.; Hann, S. LC-MS/MS analysis of phenols for classification of red wine according to geographic origin, grape variety and vintage. Food Chem. 2010, 122, 366-372. [CrossRef]

21. Pisano, P.L.; Silva, M.F.; Olivieri, A.C. Anthocyanins as markers for the classification of Argentinean wines according to botanical and geographical origin. Chemometric modeling of liquid chromatography-mass spectrometry data. Food Chem. 2015, 175, 174-180. [CrossRef] 
22. Žurga, P.; Vahčić, N.; Pasković, I.; Banović, M.; Staver, M.M. Croatian wines from native grape varieties have highly distinct phenolic (nutraceutic) profiles than wines from non-native varieties with same geographic origin. Chem. Biodivers. 2019, 16, e1900218. [CrossRef] [PubMed]

23. Rastija, V.; Srečnik, G.; Medić-Šarić, M. Polyphenolic composition of Croatian wines with different geographical origins. Food Chem. 2009, 115, 54-60. [CrossRef]

24. Ivanova-Petropulos, V.; Ricci, A.; Nedelkovski, D.; Dimovska, V.; Parpinello, G.P.; Versari, A. Targeted analysis of bioactive phenolic compounds and antioxidant activity of Macedonian red wines. Food Chem. 2015, 171, 412-420. [CrossRef] [PubMed]

25. Ma, T.-T.; Sun, X.-Y.; Gao, G.-T.; Wang, X.-Y.; Liu, X.-Y.; Du, G.-R.; Zhan, J.-C. Phenolic characterisation and antioxidant capacity of young wines made from different grape varieties grown in Helanshan Donglu wine zone (China). S. Afr. J. Enol. Vitic. 2014, 35, 321-331. [CrossRef]

26. Pereira, V.; Câmara, J.S.; Cacho, J.; Marques, J.C. HPLC-DAD methodology for the quantification of organic acids, furans and polyphenols by direct injection of wine samples. J. Sep. Sci. 2010, 33, 1204-1215. [CrossRef]

27. Raczkowska, J.; Mielcarz, G.; Howard, A.; Raczkowski, M. UPLC and spectrophotometric analysis of polyphenols in wines available in the Polish market. Int. J. Food Prop. 2011, 14, 514-522. [CrossRef]

28. Van Leeuw, R.; Kevers, C.; Pincemail, J.; Defraigne, J.O.; Dommes, J. Antioxidant capacity and phenolic composition of red wines from various grape varieties: Specificity of Pinot noir. J. Food Compos. Anal. 2014, 36, 40-50. [CrossRef]

29. Ragusa, A.; Centonze, C.; Grasso, M.E.; Latronico, M.F.; Mastrangelo, P.F.; Sparascio, F.; Maffia, M. HPLC analysis of phenols in Negroamaro and Primitivo red wines from Salento. Foods 2019, 8, 45. [CrossRef]

30. Gonçalves, J.; Silva, C.L.; Castilho, P.C.; Câmara, J.S. An attractive, sensitive and high-throughput strategy based on microextraction by packed sorbent followed by UHPLC-PDA analysis for quantification of hydroxybenzoic and hydroxycinnamic acids in wines. Microchem. J. 2013, 106, 129-138. [CrossRef]

31. Stój, A.; Szwajgier, D.; Baranowska-Wójcik, E.; Domagala, D. Gentisic acid, salicylic acid, total phenolic content and cholinesterase inhibitory activities of red wines made from various grape varieties. S. Afr. J. Enol. Vitic. 2019, 40, 1-12. [CrossRef]

32. Tomaz, I.; Maslov, L. Simultaneous determination of phenolic compounds in different matrices using phenyl-hexyl stationary phase. Food Anal. Method. 2016, 9, 401-410. [CrossRef]

33. Valentin, L.; Barroso, L.P.; Barbosa, R.M.; de Paulo, G.A.; Castro, I.A. Chemical typicality of South American red wines classified according to their volatile and phenolic compounds using multivariate analysis. Food Chem. 2020, 302, 125340. [CrossRef] [PubMed]

34. Ruocco, S.; Perenzoni, D.; Angeli, A.; Stefanini, M.; Rühl, E.; Patz, C.D.; Mattivi, F.; Rauhut, D.; Vrhovsek, U. Metabolite profiling of wines made from disease-tolerant varieties. Eur. Food Res. Technol. 2019, 245, $2039-2052$. [CrossRef]

35. Mayr, C.M.; De Rosso, M.; Dalla Vedova, A.; Flamini, R. High-Resolution mass spectrometry identification of secondary metabolites in four red grape varieties potentially useful as traceability markers of wines. Beverages 2018, 4, 74. [CrossRef]

36. Kapusta, I.; Cebulak, T.; Oszmiański, J. Characterization of Polish wines produced from the interspecific hybrid grapes grown in south-east Poland. Eur. Food Res. Technol. 2018, 244, 441-455. [CrossRef]

37. The New York Times. Available online: https://www.nytimes.com/2010/02/19/business/global/19wine.html (accessed on 19 December 2019).

38. Dobrowolska-Iwanek, J.; Gąstol, M.; Wanat, A.; Krośniak, M.; Jancik, M.; Zagrodzki, P. Wine of cool-climate areas in South Poland. S. Afr. J. Enol. Vitic. 2014, 35, 1-9. [CrossRef]

39. Samoticha, J.; Wojdyło, A.; Golis, T. Phenolic composition, physicochemical properties and antioxidant activity of interspecific hybrids of grapes growing in Poland. Food Chem. 2017, 215, 263-273. [CrossRef]

40. Socha, R.; Gałkowska, D.; Robak, J.; Fortuna, T.; Buksa, K. Characterization of Polish wines produced from the multispecies hybrid and Vitis vinifera L. grapes. Int. J. Food Prop. 2015, 18, 699-713. [CrossRef]

41. Vitis International Variety Catalogue. Available online: www.vivc.de (accessed on 19 December 2019).

42. Liu, J.; Arneborg, N.; Toldam-Andersen, T.B.; Petersen, M.A.; Bredie, W.L. Effect of sequential fermentations and grape cultivars on volatile compounds and sensory profiles of Danish wines. J. Sci. Food Agric. 2017, 97, 3594-3602. [CrossRef] 
43. Lasik-Kurdyś, M.; Gumienna, M.; Nowak, J. Influence of malolactic bacteri, a inoculation scenarios on the efficiency of the vinification process and the quality of grape wine from the Central European region. Eur. Food Res. Technol. 2017, 243, 2163-2173. [CrossRef]

44. Lasik-Kurdyś, M.; Majcher, M.; Nowak, J. Effects of different techniques of malolactic fermentation induction on diacetyl metabolism and biosynthesis of selected aromatic esters in cool-climate grape wines. Molecules 2018, 23, 2549. [CrossRef] [PubMed]

45. International Organisation of Vine and Wine. Compedium of international methods of analysis. Maximum acceptable limits of various substances contained in wine. Available online: http://www.oiv.int/js/lib/pdfjs/ web/viewer.html?file=/public/medias/2601/oiv-ma-c1-01.pdf (accessed on 8 January 2020).

46. Kapusta, I.; Cebulak, T.; Oszmiański, J. The anthocyanins profile of red grape cultivars growing in south-east Poland (Subcarpathia region). J. Food Meas. Charact. 2017, 11, 1863-1873. [CrossRef]

47. International Organisation of Vine and Wine. Compedium of international methods of analysis. Method OIV-MA-AS313-01. Available online: http://www.oiv.int/public/medias/3731/oiv-ma-as313-01.pdf (accessed on 15 March 2019).

48. International Organisation of Vine and Wine. Compedium of international methods of analysis. Method OIV-MA-AS313-15. Available online: http://www.oiv.int/public/medias/2514/oiv-ma-as313-15.pdf (accessed on 15 March 2019).

Sample Availability: Not available. 